\title{
ERRATUM
}

\section{THE ESTIMATION OF ANGULAR MISALIGNMENTS FOR ULTRA SHORT BASELINE NAVIGATION SYSTEMS. PART II: EXPERIMENTAL RESULTS - ERRATUM}

\author{
Hsin-Hung Chen
}

doi:10.1017/S0373463313000234, Published by Cambridge University Press, 9 May 2013.

The Publisher apologises for the omission of a second contract number, in the Acknowledgements section of the article.

The Acknowledgements section should read as follows:

The authors would like to thank Jia-Pu Jang and Shu-Heng Wu of Taiwan Ocean Research Institute (TORI) for their assistance in conducting the experiment. The authors also gratefully acknowledge the financial support of the National Science Council of Taiwan under contracts NSC99-2221-E-110-094 and NSC1023113-P-110-004.

\section{REFERENCE}

Chen, H-H. The Estimation of Angular Misalignments for Ultra Short Baseline Navigation Systems. Part II: Experimental Results. The Journal of Navigation. Published by Cambridge University Press, 9 May 2013. doi: 10.1017/S0373463313000234. 